\title{
Efek Gliserin sebagai Humectan Terhadap Sifat Fisik dan Stabilitas Vitamin C dalam Sabun Padat
}

\section{The Effect of Glycerin as Humectant Towards Physical Properties and Stability of Vitamin $C$ in Solid Soap}

\author{
Anita Sukmawati*, Ms. Nur-ainee Laeha, dan Suprapto \\ Fakultas Farmasi, Universitas Muhammadiyah Surakarta \\ Jl. A Yani Tromol Pos 1, Pabelan Kartasura Surakarta 57102 Telp.(0271)717417 \\ *Email: anita.sukmawati@ums.ac.id
}

\begin{abstract}
Abstrak
Gliserin adalah suatu humektan yang sering digunakan dalam produk kosmetik terutama dalam sabun. Penelitian ini dilakukan untuk mengetahui bagaimana pengaruh gliserin terhadap sifat fisik sabun yaitu $\mathrm{pH}$, kekerasan dan stabilitas busa, dan juga terhadap stabilitas vitamin $\mathrm{C}$ dalam sabun selama masa penyimpanan selama 8 minggu. Vitamin $\mathrm{C}$ diformulasikan dalam sediaan sabun dengan variasi konsentrasi gliserin yang berbeda yaitu 5\%, 10\% dan $20 \%$. Evaluasi pada sediaan sabun meliputi uji pH, uji kekerasan sabun, uji stabilitas busa dan uji stabilitas vitamin $\mathrm{C}$ dalam penyimpanan selama 8 minggu. Hasil yang didapat dianalisis statistik menggunakan software SPSS versi 16 for windows. Hasil penelitian menunjukkan bahwa gliserin tidak berpengaruh signifikan terhadap nilai $\mathrm{pH}$ sabun dengan nilai signifikansi $\mathrm{P}=0,26>0,05$, sedangkan konsentrasi gliserin yang semakin meningkat menghasilkan sabun yang makin lunak. Perbedaan konsentrasi gliserin terhadap stabilitas busa sabun menunjukkan bahwa peningkatan konsentrasi gliserin tidak berpengaruh signifikan terhadap peningkatan stabilitas busa sabun vitamin C. Stabilitas busa yang paling baik terdapat pada sabun padat yang mengandung gliserin $10 \%$. Gliserin juga berpengaruh terhadap stabilitas vitamin $\mathrm{C}$ dalam sediaan sabun yaitu semakin tinggi konsentrasi gliserin maka stabilitas vitamin $\mathrm{C}$ juga makin baik ditunjukkan pada sabun formula III yang mengadung gliserin $20 \%$ mengalami penurunan kadar vitamin C sebanyak $49,48 \%$, sedangkan pada sabun yang mengandung gliserin $5 \%$ dan $10 \%$, berturut-turut mengalami penurunan kadar vitamin $\mathrm{C}$ sebanyak 77,98\% dan 60,67\% selama masa penyimpanan 8 minggu.

Kata kunci: Sabun, Gliserin, Vitamin C
\end{abstract}

\begin{abstract}
Glycerin is a humectant that is used frequently for cosmetics, especially in soaps. This study was conducted to determine the influence glycerin on the physical properties of glycerin soap including pH, soap hardness, foam stability, and also on the stability of vitamin $C$ in the soap during 8 weeks storage. Vitamin $C$ is formulated in soap with various concentrations of glycerin i.e 5\%, $10 \%$ and $20 \%$. Evaluation of the soap preparations include a $\mathrm{pH}$ test, soap hardness, foam stability test and evaluation on the stability of vitamin $C$ for 8 weeks and the results obtained will be statistically analyzed using SPSS version 16 for windows by the Kruskal-Wallis method on the results test of $\mathrm{pH}$ and soap hardness, and using one way ANOVA method for evaluating foam stability. The results showed that glycerol did not significant influence on the $\mathrm{pH}$ value of soap with a significance value of $P=0.26>0.05$, while increasing the concentration of glycerin in the soap increased products softness. The foam stability testing showed that the difference in the concentration of glycerin on soap had no significant effect on improving the stability of foam. The best foam stability was found in vitamin $C$ soap containing glycerine 10\%. Glycerin also affected the stability of vitamin $C$ in the soap. The stability of vitamin $C$ is increased related to the increasing glycerin concentration in soap as demonstrated in formula III, which contained $20 \%$ glycerin and had $49.48 \%$ reducing in level of vitamin C, while the soap containing glycerine $5 \%$ and $10 \%$, had decreased $77.98 \%$ and $60.67 \%$ respectively in level of vitamin $C$ during the storage period of 8 weeks.
\end{abstract}

Keywords: Soap, Glycerin, Vitamin C

PHARMACON: Jurnal Farmasi Indonesia 


\section{PENDAHULUAN}

Sabun adalah senyawa natrium dengan asam lemak yang digunakan sebagai bahan pembersih tubuh, berbentuk padat, berbusa, dengan atau penambahan lain serta tidak menyebabkan iritasi pada kulit. Sabun merupakan pembersih yang dibuat dengan reaksi kimia antara basa natrium atau kalium dengan asam lemak dari minyak nabati atau lemak hewani (SNI, 1994). Pemilihan jenis asam lemak menentukan karakteristik sabun yang dihasilkan, kerena setiap jenis asam lemak akan memberikan sifat yang berbeda pada sabun (Corredoira dan Pandolfi, 1996).

Humektan merupakan suatu bahan yang dapat mempertahankan air pada sediaan. Humektan berfungsi untuk memperbaiki stabilitas suatu bahan dalam jangka waktu yang lama, selain itu untuk melindungi komponen-komponen yang terikat kuat di dalam bahan termasuk air, lemak, dan komponen lainnya. Humektan yang sering digunakan dalam industri kosmetik adalah gliserin (Jackson, 1995). Gliserin digunakan sebagai humektan karena gliserin merupakan komponen higroskopis yang dapat mengikat air dan mengurangi jumlah air yang meninggalkan kulit. Efektifitas gliserin tergantung pada kelembaban lingkungan di sekitarnya. Humektan dapat melembabkan kulit pada kondisi kelembaban tinggi. Gliserin dengan konsentrasi 10\% dapat meningkatkan kehalusan dan kelembutan kulit (Mitsui, 1997).

Vitamin C mempunyai peranan yang penting dalam mensintesis kollagen, yang merupakan komponen penting kulit dan jaringan pengikat (Sofro et al, 1990). Fungsi dari vitamin $C$ salah satunya adalah sebagai antioksidan, yaitu substansi yang memberikan elektron kepada radikal bebas dan membantu menstabilkan radikal bebas sehingga melindungi sel dari kerusakan (Williams dan Wilkins, 2011).

Gliserin yang berfungsi sebagai humektan sering digunakan dalam fomulasi sediaan sabun, oleh karena itu, dalam penelitian ini dilakukan evaluasi mengenai pengaruh penambahan gliserin berbagai konsentrasi terhadap sifat-sifat fisik dari sabun, dan kestabilan vitamin $\mathrm{C}$ selama masa penyimpanan tertentu.

\section{METODE PENELITIAN}

\section{Alat dan Bahan}

\section{Alat}

Alat yang digunakan adalah alat-alat gelas, baskom, penangas air, bahan plastik keras untuk mencetak sabun, timbangan analitik, pH meter, labu takar, alat uji kekerasan tablet ( LIH-1 tablet hardness tester), alat sentrifuge (centrifuge PLC series $\mathrm{K}$ ), climatic oven (Memmert HPP108) dan peralatan spektrofotometer UV.

\section{Bahan}

Minyak kelapa sawit, minyak zaitun, natrium hidroksida $(\mathrm{NaOH})$, aquades, gliserin, cocamid dietanolamin, vitamin $\mathrm{C}$ dan kloroform.

\section{Formulasi sabun padat vitamin $\mathbf{C}$}

Dibuat 3 rancangan formulasi sabun dengan menggunakan konsentrasi gliserin dan yang berbeda-beda yaitu : $5 \%, 10 \%$, dan 20\% (Tabel 1.)

\section{Cara pembuatan sabun}

Bagian A dicampur dan dipanaskan sampai suhu $60-70^{\circ} \mathrm{C}$. Bagian B dicampur dan diaduk sampai larut, dan bagian $\mathrm{C}$ juga dicampur dan diaduk sampai homogen. Dicampurkan bagian B ke dalam bagian A, diaduk hingga tercampur homogen disebut bagian 1, kemudian bagian $\mathrm{C}$ dimasukkan ke dalam bagian 1 sambil diaduk sampai larut dan tercampur, didinginkan sampai suhu 50$60^{\circ} \mathrm{C}$, terakhir dicampurkan bagian $\mathrm{D}$ diaduk dan dituang ke dalam cetakan dan didiamkan hingga 24 jam kemudian dikeluarkan sabun dari cetakan.

\section{Evaluasi sediaan sabun}

Derajat keasaman (pH). Sampel dihaluskan kemudian ditimbang sebanyak satu gram dimasuk ke dalam beker glas. Akuades yang memiliki $\mathrm{pH} 7$ ditambahkan sebanyak $10 \mathrm{~mL}$ dan diaduk sampai larut 
Tabel 1. Formulasi sabun padat vitamin C

\begin{tabular}{clcccc}
\hline Bagian & \multicolumn{1}{c}{ Bahan } & Satuan & FI & FII & FIII \\
\hline \multirow{2}{*}{ A } & Minyak kelapa sawit & $\mathrm{g}$ & 30 & 30 & 30 \\
& Minyak zaitun & $\mathrm{g}$ & 5 & 5 & 5 \\
$\mathrm{~B}$ & $\mathrm{NaOH}$ & $\mathrm{g}$ & 8 & 8 & 8 \\
& Akuades & $\mathrm{g}$ & 20 & 20 & 20 \\
$\mathrm{C}$ & Cocamid DEA & $\mathrm{g}$ & 27 & 22 & 12 \\
& Gliserin & $\mathrm{g}$ & 5 & 10 & 20 \\
$\mathrm{D}$ & Vitamin C & $\mathrm{g}$ & 2 & 2 & 2 \\
& Akuades & $\mathrm{g}$ & 3 & 3 & 3 \\
\hline \multirow{2}{*}{ Total } & & $\mathrm{G}$ & 100 & 100 & 100 \\
\hline
\end{tabular}

kemudian dilakukan pengukuran $\mathrm{pH}$ dengan cara memasukan $\mathrm{pH}$ meter yang telah dikalibrasi dengan $\mathrm{pH} 4,7$, dan 9. Selanjutnya $\mathrm{pH}$ meter didiamkan beberapa saat hingga didapatkan $\mathrm{pH}$ yang tetap.

Uji kekerasan sabun. Pengukuran tingkat kekerasan sabun padat dilakukan dengan menggunakan alat pengukuran kekerasan tablet. Kekerasan suatu sabun yang diukur akan menunjukkan seberapa berat kekuatan alat yang dibutuhkan sehingga dapat merubahkan bentuk sabun. Hasil pengukuran kekerasan sabun didapat dengan membaca angka yang dinyatakan pada alat tersebut. Semakin tinggi angka yang didapat, berarti sabun tersebut semakin keras. Pengukuran tingkat kekerasan sabun dilakukan dengan cara sabun dipotong menjadi segi empat dengan masing-masing dimensi 1 , dipasang pada alat uji dan diukur kekerasannya sebanyak 10 kali pada masing- masing formulasi.

Uji stabilitas busa. Uji stabilitas busa dilakukan dengan menggunakan metode Cylinder shake yaitu dengan mengambil sampel sabun padat satu gram dimasukkan ke dalam tabung reaksi yang telah diberi skala kemudian ditambahkan akuades $5 \mathrm{~mL}$ kemudian tabung dikocok kuat hingga timbul busa sampai penuh tabung reaksi, kemudian diukur tinggi busa sabun pada waktu 5, 10, 15, 20, 25 dan 30 menit pada masing-masing konsentrasi sabun padat selanjutnya hasil yang terdapat dihitung dengan menggunakan rumus (1) .

Stabilitas busa $=$

$\frac{\text { Tinggi busa akhir }(\mathrm{mm})}{\text { Tinggi busa awal }(\mathrm{mm})} \times 100 \%$

\section{Uji stabilitas vitamin $\mathbf{C}$}

Uji stabilitas vitamin $\mathrm{C}$ dilakukan pemantauan kadar vitamin $\mathrm{C}$ dalam waktu penyimpanan setiap 7 hari selama 8 minggu. Kadar vitamin $\mathrm{C}$ ditentukan dengan menggunakan metode spektrofotometri UV dengan cara dibuat larutan stok dengan konsentrasi $1000 \mu \mathrm{g} / \mathrm{mL}(0,1 \%)$, dimasukkan dalam kuvet dan dicari panjang gelombang maksimal ( $\lambda$ max). Dibuat kurva baku dari larutan stok dengan seri konsentrasi 500 $\mu \mathrm{g} / \mathrm{mL}, 250 \mu \mathrm{g} / \mathrm{mL}, 125 \mu \mathrm{g} / \mathrm{mL}, 62,5 \mu \mathrm{g} / \mathrm{mL}$, $31,25 \mu \mathrm{g} / \mathrm{mL}, 15,625 \mu \mathrm{g} / \mathrm{mL}, 7,8125 \mu \mathrm{g} / \mathrm{mL}$, $3,906 \mu \mathrm{g} / \mathrm{mL}$, dan $1,953 \mu \mathrm{g} / \mathrm{mL}$ dibaca absorbansi pada $\lambda$ max yang sudah ditentukan kemudian dibuat persamaan regresi linier, hubungan antara konsentrasi (x) vs absorbansi (y) sehingga akan dapat persamaan kurva baku $\mathrm{y}=\mathrm{bx}+\mathrm{a}$.

Penentuan kadar vitamin C dilakukan dengan menimbang sampel sabun sebanyak 1 $\mathrm{g}$ dilarutkan dalam larutan akuades : kloroform sebanyak 8:2 $\mathrm{mL}$ dalam tabung sentrifuge dipasangkan pada alat sentrifuge dan diputar dengan kecepatan 1000 kali per menit selama 5 menit sehingga terbentuk dua lapisan antara cairan bening (supernatan) 


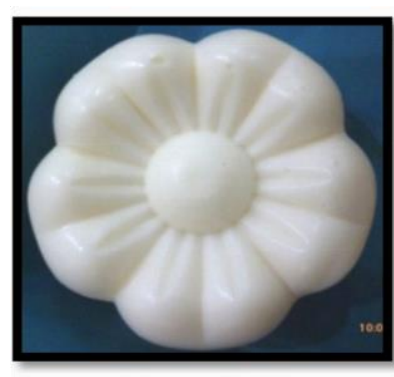

Formulasi I

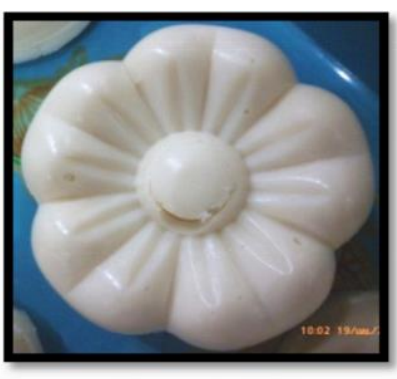

Formulasi II

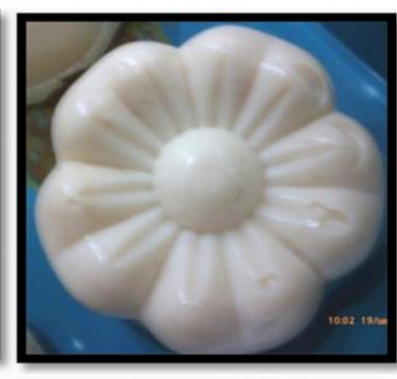

Formulasi III

Gambar 1. Hasil sabun padat vitamin C dengan konsentrasi gliserin 5\% (F1); $10 \%$ (F2) dan 20\% (F3)

yaitu dari vitamin $\mathrm{C}$ yang larut dalam akuades dan endapan dari komponen minyak yang larut dalam kloroform. Larutan bening diambil sebanyak $1 \mathrm{~mL}$ dan ditambahkan akuades $10 \mathrm{ml}$ dalam labu takar dan dimasukkan ke dalam kuvet untuk mengukur absorbansi pada $\lambda$ max tertentu. Dibuat replikasi sebanyak 3 kali. Data pengukuran absorbansi sampel dimasukkan ke dalam persamaan kurva baku (sebagai faktor y), maka akan didapat x sebagai kadar sampel.

Validasi metode dilakukan untuk mengetahui seberapa valid metode yang di gunakan dengan menggunakan metode adisi standar yaitu sabun yang tidak mengandung vitamin $\mathrm{C}$ ditambah vitamin $\mathrm{C}$ dari luar dengan kadar $1 \mathrm{mg} / \mathrm{mL}$ dan dilakukan seperti perlakuan pada sampel, kemudian hasil yang terdapat dimasukkan dalam perhitungan recovery untuk mengetahui berapa persen akurasi yang terdapat.

\section{Analisis Data}

Ada atau tidaknya perbedaan yang bermakna pada data sifat fisik sediaan sabun padat termasuk $\mathrm{pH}$, kekerasan dan stabilitas busa dengan berbagai variasi konsentrasi gliserin dalam sabun padat, dilakukan analisis statistik Kruskal-Wallis, uji Post hoc dan uji ANOVA satu jalan dengan program SPSS versi 16 for Windows.

\section{HASIL DAN PEMBAHASAN}

\section{Evaluasi Sediaan Sabun Padat}

Evaluasi sediaan sabun padat vitamin $\mathrm{C}$ pada percobaan ini dilakukan untuk mengetahui bagaimana sifat fisik sabun dan bagaimana kestabilan vitamin $\mathrm{C}$ setelah diformulasikan dalam sediaan sabun padat dengan menggunakan konsentrasi gliserin yang berbeda. Uji yang dilakukan meliputi pemeriksaan sifat fisik sabun padat yaitu uji pH, uji kekerasan sabun, uji stabilitas busa, dan uji stabilitas vitamin $\mathrm{C}$ dalam masa penyimpanan selama 8 minggu.

Sabun yang dihasilkan dengan pemerian warna putih, keras dan permukaan halus dengan bentuk sesuai dengan bentuk cetakkannya (Gambar 1) dan berat rata- rata 99,32 $\pm 0,17 \mathrm{~g}$.

Produk kosmetika terutama sabun memiliki karakteristik fisik yang sangat penting, yaitu nilai $\mathrm{pH}$. Jumlah alkali yang ada dalam sabun mempengaruhi besarnya nilai $\mathrm{pH}$ (Jellinek,1970). Pembuatan sabun dalam penelitian ini juga melibatkan pemakaian sejumlah besar natrium hidroksida sebagai sumber alkali. Nilai $\mathrm{pH}$ sabun setelah dilakukan formulasi didapatkan $\mathrm{pH}$ rata-rata pada sabun yang mengandung gliserin 5\% sebesar 10,50 $\pm 0,02$ sabun yang mengandung gliserin $10 \%$ sebesar $10,41 \pm 0,023$ dan pada sabun yang mengandung gliserin $20 \%$ sebesar 10,63 \pm 0,0115 (Gambar 2). Berdasarkan hasil uji statistik Kruskal-Wallis menunjukan bahwa tidak ada perbedaan konsentrasi gliserin terhadap nilai $\mathrm{pH}$ sabun vitamin $\mathrm{C}$ dengan nilai signifikasi $\mathrm{P}=0,26>0,05$.

Hasil penelitian menunjukkan nilai ratarata kekerasan sabun padat berkisar antara $0,498 \mathrm{~kg}$ hingga $0,872 \mathrm{~kg}$ (Gambar 3). Nilai tertinggi diperoleh dari sabun yang 
mengandung gliserin 5\% dengan nilai $0,872 \pm$ $0,081 \mathrm{~kg}$, sedangkan yang paling lunak adalah sabun yang mengandung gliserin $20 \%$ dengan nilai $0,498 \pm 0,057 \mathrm{~kg}$. Dari hasil yang didapat maka sabun yang memiliki kekerasan paling tinggi adalah sabun yang menggandung gliserin paling sedikit yaitu 5\% sedangkan sabun yang paling lunak adalah sabun yang mengandung gliserin paling tinggi yaitu $20 \%$. Berdasarkan hasil uji statistik Kruskal-Wallis menunjukkan bahwa tidak terdapat perbedaan hubungan konsentrasi gliserin terhadap kekerasan sabun vitamin $\mathrm{C}$ secara signifikan dengan nilai Sig. 0,00 (Sig.< 0,05), sehingga dilakukan uji Post hoc yang menunjukkan bahwa kekerasan sabun dengan gliserin $5 \%$ berbeda nyata dengan sabun dengan gliserin $10 \%$ dan $20 \%$. Oleh karena itu dapat disimpulkan bahwa dengan semakin tinggi konsentrasi gliserin maka akan menghasilkan sabun yang semakin lunak.

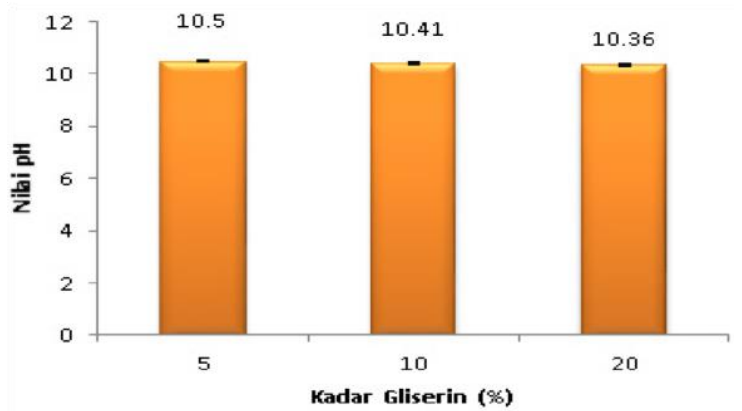

Gambar 2. Hubungan antara kadar gliserin dan nilai pH sabun vitamin $\mathrm{C}$, bar menunjukkan nilai SD dari 3 kali replikasi

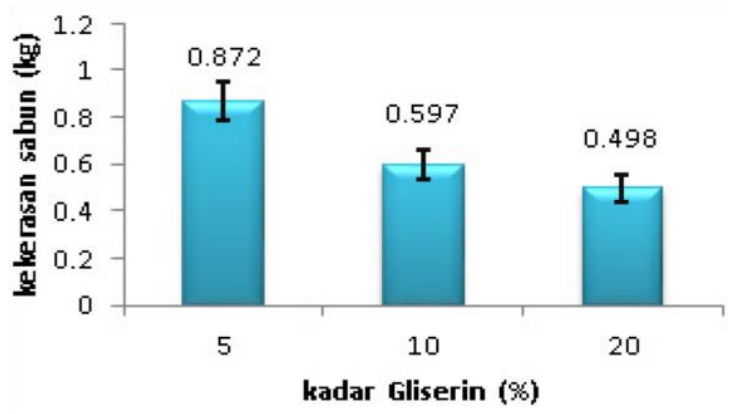

Gambar 3. Hubungan antara kadar gliserin dan kekerasan sabun vitamin $\mathbf{C}$, bar menunjukkan nilai SD dari 10 kali replikasi

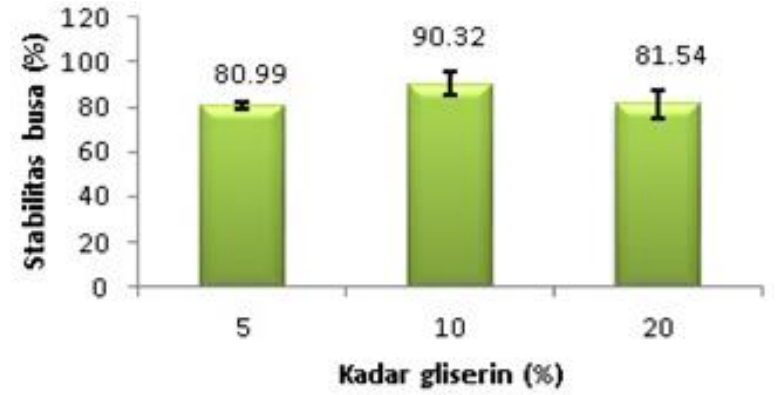

Gambar 4. Hubungan antara kadar gliserin dan stabilitas busa sabun vitamin $\mathrm{C}$, bar menunjukkan nilai SD dari 3 kali replikasi

Busa adalah dispersi gas dalam cairan yang distabilkan oleh suatu zat pembusa, merupakan struktur yang relatif stabil dan terdiri atas kantong-kantong udara yang terbungkus dalam lapisan tipis. Busa yang banyak dan stabil lebih disukai daripada busa yang sedikit atau tidak stabil.

Pengukuran terhadap kestabilan busa pada sabun yang diteliti menunjukkan nilai tertinggi diperoleh dari sabun yang mengandung gliserin $10 \%$ yaitu 90,32 \% 4,95, sementara nilai terendah diperoleh dari sabun yang mengandung gliserin $5 \%$ yaitu $80,99 \% \pm 1,58$ (Gambar 3). Hasil uji statistik dengan metode ANOVA satu jalan menunjukkan bahwa peningkatan konsentrasi gliserin tidak berpengaruh secara signifikan terhadap peningkatan stabilitas busa sabun vitamin $\mathrm{C}$ dengan hasil nilai signifikasi $\mathrm{P}=0,89>0,05$. Penggunaan konsentrasi gliserin yang berbeda akan menghasilkan tingkat stabilitas busa yang tidak berbeda. Stabilitas busa yang paling tinggi diperoleh pada formula II yaitu dengan nilai sebesar $90,32 \%$.

Uji validasi metode analisis dilakukan untuk melihat seberapa valid metode yang digunakan. Parameter yang digunakan adalah persen recovery dengan cara dibuatkan larutan standard vitamin C 10,8 mg /10 mL akuades, diambil 0,2 $\mathrm{mL}$ dari larutan tersebut kemudian dimasukan kedalam $1 \mathrm{~g}$ sampel sabun yang tanpa vitamin $\mathrm{C}$ dan ditambahkan $10 \mathrm{~mL}$ akuades sehingga terdapat kadar 
Tabel 2. Hasil uji validasi metode penentuan kadar vitamin $\mathrm{C}$ dalam sabun dengan spektrofotometri UV dengan parameter \% recovery

\begin{tabular}{|c|c|c|c|c|c|c|}
\hline Replikasi & Absorbansi & $Y=0,046 x+0,287$ & $\begin{array}{c}\text { Kadar } \\
\text { terukur } \\
(\mu \mathrm{g} / \mathrm{mL})\end{array}$ & $\begin{array}{c}\text { Kadar } \\
\text { sebenarnya } \\
(\mu \mathrm{g} / \mathrm{mL})\end{array}$ & $\begin{array}{l}\% \\
\text { recovery } \\
\times 100 \%\end{array}$ & $\overline{\mathbf{x}} \pm \mathrm{SD}$ \\
\hline 1 & 1,280 & $1,280=0,046 x+0,287$ & 21,58 & 21,6 & $99,90 \%$ & \multirow{3}{*}{$\begin{array}{r}97,21 \% \\
\pm 2,61\end{array}$} \\
\hline 2 & 1,228 & $1,228=0,046 x+0,287$ & 20,45 & 21,6 & $94,67 \%$ & \\
\hline 3 & 1,252 & $1,252=0,046 x+0,287$ & 20,97 & 21,6 & $97,08 \%$ & \\
\hline
\end{tabular}

sebenarnya adalah $21,6 \mu \mathrm{g} / \mathrm{mL}$. Pengujian yang dilakukan adalah sama seperti uji pada sampel sebelumnya.

Hasil persen recovery yang didapat adalah 97,22 \% sedangkan nilai persen recovery yang baik adalah sekitar $97-103 \%$ sehingga dapat disimpulkan bahwa metode penetapan kadar vitamin $\mathrm{C}$ secara spektrofotometri UV yang digunakan adalah valid (Tabel 2).

Uji stabilitas vitamin $C$ dilakukan untuk mengetahui bagaimana pengaruh perbedaan konsentrasi gliserin dalam sediaan sabun terhadap stabilitas vitamin $\mathrm{C}$ selama

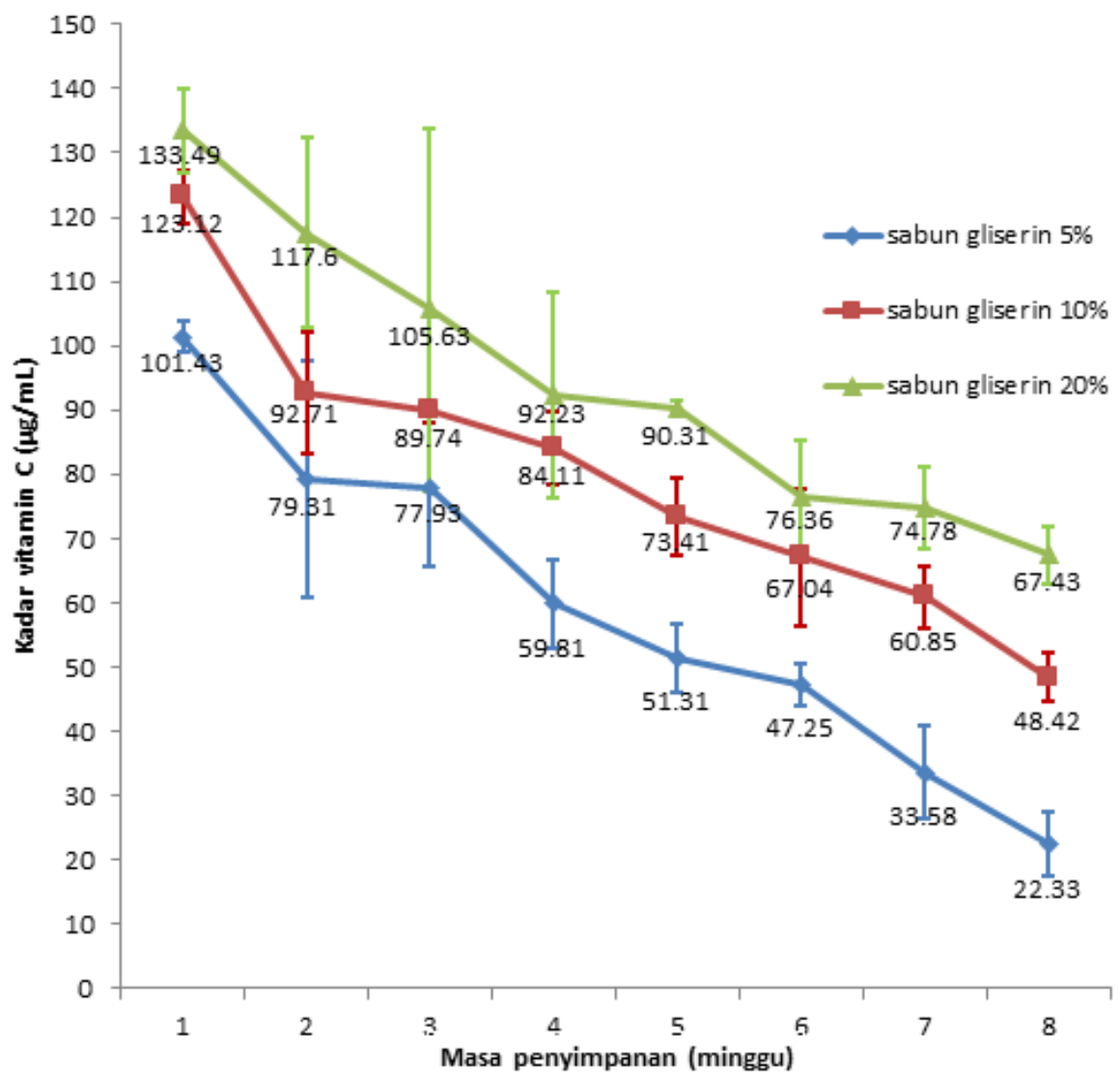

Gambar 5. Hubungan antara lama penyimpanan sabun selama 8 minggu pada suhu $25{ }^{\circ} \mathrm{C}$ dengan kadar vitamin $\mathrm{C}$ dalam sabun dengan bervariasi konsentrasi gliserin yaitu $5 \%, 10 \%$ dan $20 \%$, bar menunjukkan nilai SD dari 3 kali replikasi 
penyimpanan 8 minggu. Kadar vitamin $\mathrm{C}$ dipantau setiap minggu selama 8 minggu dengan metode spektrofotometri UV dan sampel sabun disimpan dalam alat climatic chamber dengan suhu terjaga $25^{\circ} \mathrm{C}$ pada tekanan 1 atm. Pembacaan absorbansi dilakukan pada panjang gelombang $261 \mathrm{~nm}$.

Hasil yang terdapat pada sabun dengan gliserin 5\% kadar vitamin $\mathrm{C}$ yang hilang adalah $78,71 \mu \mathrm{g} / \mathrm{mL}$ atau sekitar $77,98 \%$ dari kadar totalnya dengan kecepatan 1,38-21,73 $\mu \mathrm{g} / \mathrm{mL}$ perminggu, sedangkan sabun yang mengandung gliserin $10 \%$ kadar vitamin C yang hilang adalah sebesar $74,71 \mu \mathrm{g} / \mathrm{mL}$ atau sekitar 60,67 \% dengan kecepatan 2,97 $30,41 \mu \mathrm{g} / \mathrm{mL}$ per minggu selama 8 minggu dan pada sabun dengan gliserin $20 \%$ kadar vitamin $\mathrm{C}$ yang hilang sebanyak $66,06 \mu \mathrm{g} / \mathrm{mL}$ atau sekitar 49,48\% dari kadar total dengan kecepatan 1,58-15,89 $\mu \mathrm{g} / \mathrm{mL}$ per minggu selama masa penyimpanan dari minggu pertama hingga minggu ke 8 sebagaimana dapat dilihat pada gambar 10 .

Hasil yang didapat menunjukkan bahwa sabun yang paling stabil adalah sabun yang mengandung gliserin $20 \%$ karena mengalami penurunan kadar vitamin $\mathrm{C}$ yang paling sedikit dibandingkan dengan sabun yang lain yaitu sebesar 66,06 $\mu \mathrm{g} / \mathrm{mL}$ atau sekitar 49,48 $\%$ dari kadar total. Jackson (1995) mengatakan bahwa gliserin dapat digunakan untuk menjaga dan memperbaiki stabilitas suatu bahan dalam jangka waktu yang lama. Hasil percobaan (Gambar 5) menunjukkan bahwa dengan peningkatan konsentrasi gliserin maka kestabilan vitamin $\mathrm{C}$ makin terjaga sehingga pada sabun yang mengandung gliserin dengan konsentrasi tertinggi mendapatkan kadar vitamin $\mathrm{C}$ yang lebih tinggi dibandingkan dengan sabun yang konsentrasi gliserin lebih rendah.

\section{KESIMPULAN DAN SARAN \\ Kesimpulan}

Perbedaan konsentrasi gliserin dalam sabun padat vitamin $\mathrm{C}$ tidak berpengaruh terhadap nilai $\mathrm{pH}$ sabun, sedangkan kekerasan sabun semakin menurun pada konsentrasi gliserin yang makin meningkat dan menghasilkan stabilitas busa yang tidak berbeda secara bermakna. Stabilitas busa yang paling tinggi terdapat pada sabun yang mengadung gliserin $10 \%$ sebesar $90,32 \% \pm 4,95$.

Stabilitas vitamin $\mathrm{C}$ paling baik terdapat pada sabun yang mengandung gliserin $20 \%$ yaitu mengalami penurunan kadar vitamin $\mathrm{C}$ sekitar 49,48 \%, sedangkan pada sabun yang mengandung gliserin 5\% dan $10 \%$ mengalami penurunan kadar vitamin $\mathrm{C}$ sebesar berturutturut $77,98 \%$ dan $60,67 \%$, sehingga dapat disimpulkan bahwa semakin tinggi konsentrasi gliserin dalam sabun maka stabilitas vitamin $\mathrm{C}$ dalam sabun juga semakin baik.

\section{Saran}

Pada uji stabilitas vitamin C sebaiknya diukur kadar vitamin $\mathrm{C}$ dalam sabun mulai dari minggu ke 0 .

\section{Daftar Pustaka}

Badan Standarisasi Nasional, 1994, Standar Mutu Sabun Mandi, SNI 06-3532-1994, Dewan Standarisasi Nasional, Jakarta.

Corredoira R.A. dan Pandolfi A.R., 1996, Raw Materials And Their Pretreatment For Soap Production. Di dalam Spitz, L. (ed)., 1996, Soaps and Detergents, A Theoretical and Practical Review. AOCS Press, Illinois.

Jackson, E.B., 1995, Sugar Confectionery Manufacture, Second Edition, 89, Cambridge University Press, Cambridge. 
Jellinek JS., 1970, Formulation and Function of Cosmetics. New York: Wiley-Interscience.

Mitsui T., 1997, New Cosmetic Science. Elseveir Science, B.V. Amsterdam, Netherlands.

Williams \& Wilkins, 2011, Ilmu Gizi Menjadi Sangat Mudah Edisi Kedua, Diterjemah Oleh Linda, Aryandhito Widhi Nugroho \& Niko Santoso, EGC, Jakarta. 